\title{
New urban developments and commuter rail:: Madrid case study
}

\section{Francisco Calvo PhD}

Associate Professor, TRYSE Research Group, Department of Civil Engineering, University of Granada, Granada, Spain (corresponding author: fjcalvo@ugr.es)

\section{Juan de Oña PhD}

Professor, TRYSE Research Group, Department of Civil Engineering, University of Granada, Granada, Spain
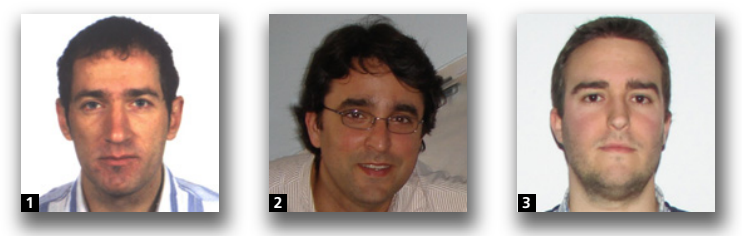

3 Fernando Arán CEng

Researcher, TRYSE Research Group, Department of Civil Engineering, University of Granada, Granada, Spain

This study describes the influence on population and land use of the recent inauguration of commuter rail stations in the metropolitan area of Madrid (Spain) in the period 2000-2011. Population growth in recent residential developments in the vicinity of new commuter rail stations was found to be greater than in comparable areas lacking any urban railway. Moreover, the growth in population near new stations was greater than in the broader study area where they are located, the metropolitan ring of Madrid. The settling of inhabitants nearby is a trend seen to accelerate shortly after inauguration of these new commuter stations. This effect is considerably stronger in the zone nearest the station. Such findings underline the positive influence that a quality public transport system may have on urban development.

\section{Notation}

\section{a}

$a_{i}$

$a_{j}^{\prime} \quad$ area of census section $j$ within catchment area of station

$i . . n \quad$ census section fully included in catchment area of station

$j . . . m$ census section partially included in catchment area of station

$P \quad$ population served by station

$p_{i} \quad$ population in census section $i$

$p_{j} \quad$ population in census section $j$

$t_{n} \quad$ year in relation to inauguration

$x \quad$ year

$y \quad$ inhabitants

\section{Introduction}

The city of Madrid has a well-developed local railway network. In the span of a decade, from 2000 to 2011, it grew $45.4 \mathrm{~km}$, encompassing 13 new stations (ADIF, 2011; RENFE, 2011). Meanwhile, as of the year 2000, important urban developments began to be built in previously non-urbanised areas in the periphery of Madrid, and some of them were favoured by the proximity of new commuter stations. The capital of Spain is therefore an appropriate context for assessing the influence of commuter rail stations on changes in land use and population settlement.

The objective of this study is to determine how construction of new commuter rail stations may have influenced population trends and land use development in Madrid. The paper is organised as follows: Section 2 offers a review of the literature. Section 3 describes the study area. Section 4 expounds the methodology. Sections 5 and 6, respectively, address analyses of the evolution and concentration of local populations. Finally, conclusions are briefly given in Section 7.

\section{Literature review}

A city's transit system generates demand for transportation while also providing the resources (infrastructure and transportation services) to meet this demand (Cascetta, 2009). A transport system sometimes expands as an 'afterthought', to meet the needs of existing settlement and development patterns, or to accommodate development already underway, rather than in response to land use master plans (Giuliano, 1999).

However, the locational focus of residence and employment is by no means independent of the surrounding transport system. Changes in transport facilities have an impact on the development of an area, attracting population and economic activity. Such factors should be taken into consideration during urban planning processes (Ortúzar and Willumsen, 2001).

There are numerous ways to analyse accessibility to public transport, stemming from particular spatial conceptualisations and measurements (Jones, 1981; Koenig, 1980; Pirie, 1979; Reggiani, 1998). One simple indicator of public transport 
accessibility is the cumulative opportunities measure, which simply sums up the population or economic activity within a given distance or time from the public transport station. For example, Gutiérrez et al. (2000) used a time limit indicator to study expansion of the Madrid underground in 1995-1999, and found that the population had increased more in a radius of $0-300 \mathrm{~m}$ than in the ring of $300-600 \mathrm{~m}$.

According to Pagliara and Papa (2010), the population impact of a rail-based public transport system will vary depending on the specific location of the stations and the network itself. Their work, comparing property prices and population growth in catchment areas served by new rail lines and control areas in Naples (Italy), was presented in the context of a review of the literature on public transport systems and their impact on development. For example, studies of New York's and Washington's rail systems showed that most population growth occurs in the catchment areas of peripheral stations, located at the end of the lines. In Naples, the positive impact around new stations occurred only in a few cases.

Studies involving Madrid Underground lines M-1 and M-10 and light rail lines ML-1 and ML-2 by Calvo et al. (2013a, 2013b) showed that average population growth around new stations was much greater than in similar areas with no urban rail. García-López (2012) found that rail stations contributed to increasing population in suburban areas in Barcelona.

Du and Mulley (2007) found that new urban rail lines can play a key role in attracting population and businesses to certain areas of a city. However, accessibility is only one factor influencing growth. Other significant elements include the regional real estate market, availability of building land, the emergence of new forms of urbanisation, changes in vehicle fleets, urban decline in city centres and how well a new line connects to the city centre.

Kasraian et al. (2016) carried out a long-term study on the simultaneous development of rail transport and urbanisation in the Ranstad (Netherlands). They found that new stations, when located in undeveloped areas, prompted further growth, increasing the likelihood of more urbanisation in their vicinity.

Dong (2016) tested the impacts of rail transit on housing development around suburban rail stations in Portland (Oregon, USA), a region with multiple supportive transit-oriented development policies. $\mathrm{He}$ found that housing developments grew much faster in the quarter-mile catchment areas around suburban stations than the regional average, and that faster density increases were associated with more vacant land zoned for high-density and mixed-use purposes. The author concludes that rail transit can guide suburban residential development in neighbourhoods with sufficient vacant land.

The influence of urban rail facilities when choosing a residential location is also reflected by a study of the Hudson-Bergen light rail system in New Jersey (USA). In this case, Liu et al. (2016) found that among light rail passengers who moved to the vicinity of the stations in the 5 years prior to the survey, two-thirds $(69 \%)$ claimed that proximity to the light rail service was a 'somewhat' or 'very' important consideration.

In short, much research has been dedicated to assessing the impact of new rail transport lines on attracting population. The generalised conclusion is that commuter services tend to have a positive influence on population growth, but effects can vary substantially owing to specific conditions.

\section{Scope of the study}

The scope of the study is Madrid and its metropolitan area, which comprises 28 towns.

\subsection{Population}

The Madrid metropolitan area is the most populated one in Spain (3.3 million residents in the municipality of Madrid and 2.3 million in the satellite towns). From 2000 to 2011, the population in the city centre increased by $9 \cdot 7 \%$. Population growth was higher in Madrid's periphery $(15 \cdot 4 \%)$ and much higher in the satellite towns $(27 \cdot 3 \%)$ (IECM, 2011a). This is due to many factors, but the main reason is that downtown Madrid is a consolidated historical centre, surrounded by areas with a higher potential for growth and lower land prices.

\subsection{The commuter rail network}

The suburban rail service connects the city of Madrid with its metropolitan area as well as the main towns in the region of Madrid. This commuter rail network had, in 2011, ten operating lines $(370 \mathrm{~km}$ long, 89 stations and 1.385 daily train trips, transporting close to one million travellers on weekdays) (RENFE, 2011). Its recent expansion is due to the substantial increase in population and the use of private vehicles in the cities of the metropolitan ring, in order to achieve sustainable transport between Madrid and its satellite towns.

\section{Methodology}

\subsection{Zoning}

The benchmark used is the official zoning plan of the region of Madrid, which partitions the region into four concentric divisions (Figure 1). The first two (central core and periphery) make up the municipality of Madrid; the third comprises Madrid's satellite towns (metropolitan ring), and the fourth takes in the rest of the region. Thus, the Madrid metropolitan area includes the city centre, the outer areas and the satellite towns. Each area is further divided in to districts or towns (UCM, 2002).

Information regarding population was obtained from census sections, which provide the most detailed data available, based on zoning maps and demographic data. Each census section 


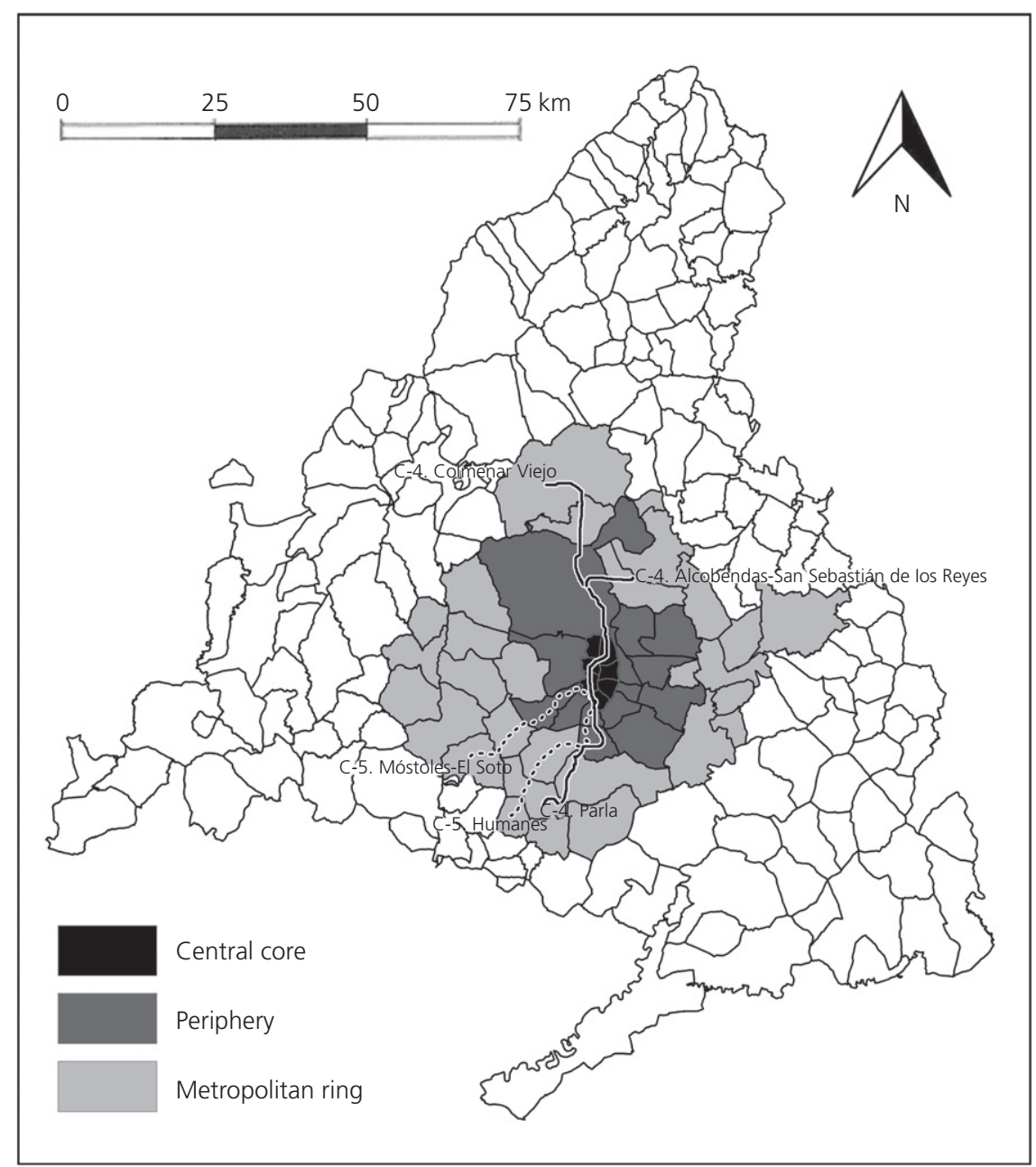

Figure 1. Region of Madrid: zoning map of the study area

provides an annual demographic value along with the corresponding spatial location (IECM, 2011a).

The zoning considered in this study is less detailed where the lines run through the city of Madrid; this is because urban development and the transport system were, in general, consolidated long before the period of study. Therefore, data from Madrid's districts - the district being larger than the census sections - was used for the population around the stations in the city of Madrid. Given the greater area of the districts, a number of stations may fall within the same district, and are hence assigned the same population data. This simplification is justified by the fact that the predominating land use and type of streets or buildings tend to be uniform at a district level. At any rate, the population around the more peripheral stations of the city of Madrid was studied in detail, in view of the census sections, to characterise more adequately the transitional population data between downtown Madrid and the satellite towns of the metropolitan ring.

\subsection{Selection of lines to study}

The criteria considered when selecting the rail lines to be analysed were

- running through a major part of the study area

- opening of important expansions of the lines and/or several stations during the time period of study

- going through both consolidated areas and newly urbanised areas.

In light of these criteria, line C-4 $(62 \cdot 2 \mathrm{~km}$ long, 18 stations $)$ and line C-5 $(45 \cdot 1 \mathrm{~km}$ long, 23 stations $)$ were chosen (Figure 1).

\subsection{Definition of the contrast areas}

Evaluation of the effects of new stations or line expansions called for establishing contrasting areas, to be compared with the areas around new stations. In this research, two types of contrast areas were considered 
- areas having no urban rail service, yet sharing urban characteristics similar to those around the new commuter rail stations; this is the classical contrast area, as used by Pagliara and Papa (2010)

- areas with commuter rail service existing before the study period (old stations).

\subsection{Determination of the station catchment area}

The station catchment area is a key factor to be accounted for in any evaluation of the impact of a new urban transport line. It comprises the geographic area affected by the public transport station. Generally speaking, the higher the quality of service provided by a new transport line (capacity, frequency, accessible destinations, intermodal connections, etc.), the larger the catchment area, as passengers will accept longer access times when the transport quality is higher. A station catchment area may be defined in terms of a radius extending out from the station. Some specific examples with particular conditions are listed below.

- The Transit Capacity and Quality of Service Manual proposes a methodology for estimating the radius of influence based on a theoretical radius of $800 \mathrm{~m}$, corrected by four factors: street connectivity, street grade, proportion of older adults in the population and accessibility of transit stop (TRB and Kittelson \& Associates, 2003).

- Research conducted by The Royal Institution of Chartered Surveyors (RICS, 2002) affirms that a station impact area can reach $1000 \mathrm{~m}$, depending on the type of public transport and specific station area features.

- Research conducted in Naples to evaluate the impact of urban rail lines analysed a radius of influence of $500 \mathrm{~m}$ around the stations (Pagliara and Papa, 2010).

- Research conducted in Minneapolis holds that, in certain areas, the station impact area may extend as far as $1400 \mathrm{~m}$ (Ko and Cao, 2010).

- Studies conducted in Madrid to evaluate the impact of rail transport modes used radii of 600,900 and $1200 \mathrm{~m}$ for commuter rail (Gutiérrez and García, 2006; Gutiérrez et al., 2000).

- To assess changes in the commercial activity around the stations of Madrid's underground line M-12, authors Mejía-Dorantes et al. (2011) used two radii -150 and $500 \mathrm{~m}$.

- Looking at 17 transit agencies with light rail service, O’Sullivan and Morrall (1996) found transit walking distance guidelines that ranged from 300 to $900 \mathrm{~m}$.

For the present study, a station catchment area of $900 \mathrm{~m}$ radius was chosen. The choice of this wide scope (close to the highest radius of the range observed in the literature) is due to the high quality of the transport of the Madrid commuter rail network. This radius of influence corresponds to a walking distance of $15 \mathrm{~min}$ (Gutiérrez et al., 2000) and avoids excessive overlap between the station catchment areas. Furthermore, the

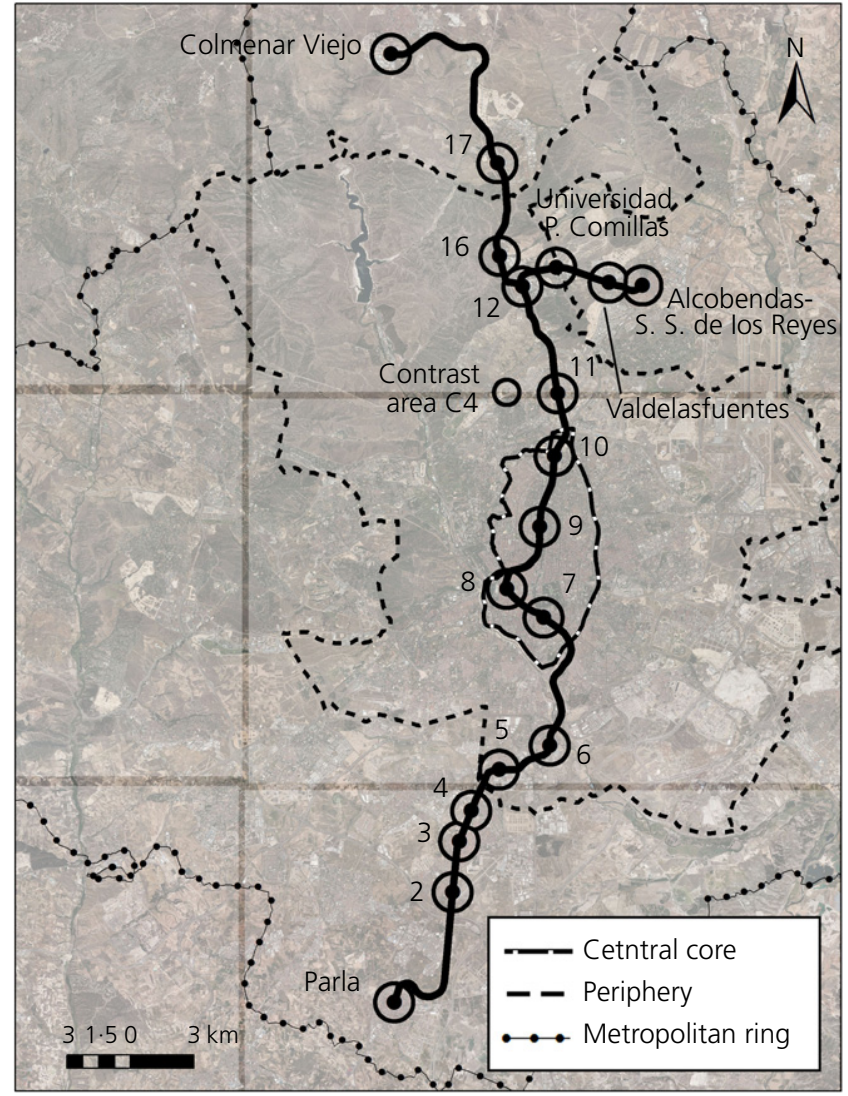

Figure 2. Commuter rail line C-4: stations, area of influence and contrast zone

station catchment area is broken down into two different radii $(600$ and $900 \mathrm{~m})$ in order to appraise the impact according to distance from the station. To compare the effects with the contrast areas that have no urban rail service, the $600 \mathrm{~m}$ radius was considered; given the vast network density in Madrid (including $370 \mathrm{~km}$ of commuter rail lines, $293 \mathrm{~km}$ of underground lines and $36 \mathrm{~km}$ of light rail lines) (CRTM, 2009), no larger areas without urban rail, yet having similar characteristics to the areas around the new stations, could be found.

\subsection{Calculation of the population around stations}

A geographic information system (ARCGIS software) was used to obtain the sphere of influence and the population served by the commuter rail stations. The method proposed by Gutiérrez (1997) and Chakraborty and Armstrong (1997) was used to estimate the population within the catchment area. This method is shown as Equation 1.

1. $P=\sum_{i=1}^{n} p_{i}+\sum_{j=1}^{m}\left(p_{j} \times \frac{a_{j}^{\prime}}{a_{j}}\right)$

where $P$ is the population served by the station; $i \ldots n$, denotes the census section fully included in the catchment area of the 


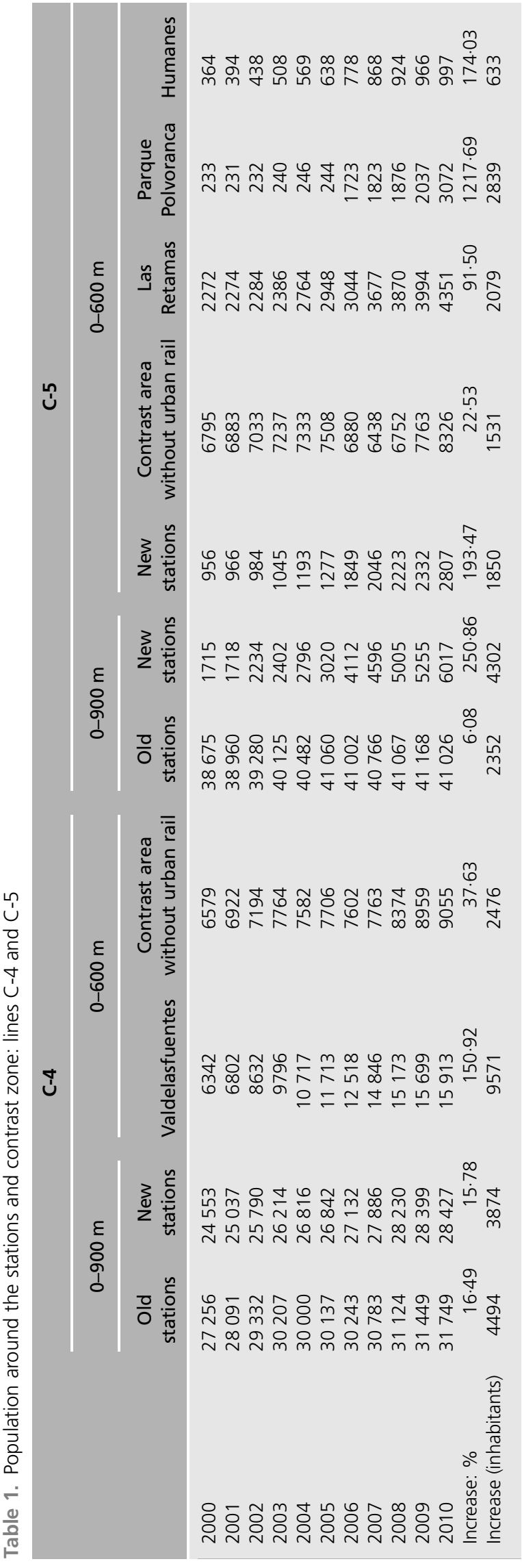

station; $p_{i}$ is the population in the census section $i ; j \ldots m$ denotes the census section partially included in the catchment area of the station; $p_{j}$ is the population in census section $j ; a_{j}^{\prime}$ is the area of census section $j$ within the catchment area of the station; and $a_{j}$ is the area of census section $j$

\section{Analysis of population evolution}

\subsection{Line C-4}

Figure 2 displays Madrid's railway line C-4. The two end stations, as well as the stations inaugurated during the period of study, are identified by their names; the rest are designated by numbers.

To evaluate jointly the effect of the inauguration of new stations on line $\mathrm{C}-4$, the evolution of the population in their area of influence can be compared (dividing the total population by the number of stations, for each type of station) with the one corresponding to the old stations (contrast zones with urban railway) and to the contrast zone without urban railway. Thus (Table 1), the increase in population around the old stations is slightly higher (percentage-wise and in absolute terms) than around the new stations. This can be attributed to the fact that the Colmenar Viejo station is situated on the outskirts of the town, by an industrial park, while the Universidad P. Comillas station services the university, and the station of Alcobendas-San Sebastián de los Reyes is situated in a well-consolidated central urban area. Thus, the only station around which new urban development took place during the period of study (hence, contributing to the rise in population around new stations) is Valdelasfuentes. This zone of recent urban development is the natural area of expansion of Alcobendas, and the new commuter rail was an additional reason behind its development.

To quantify the importance of urban development around Valdelasfuentes, the evolution of the population in its catchment area was compared with that of a contrast zone having similar urban characteristics but no kind of urban rail. In this case, the contrast zone lacking urban railway is in the new urban development of Montecarmelo (Figure 2).

As seen in Table 1, the urban and demographic expansion around Valdelasfuentes is roughly four times greater (percentage-wise and in absolute values) than in the contrast zone without urban rail. Furthermore, this growth in population is much greater than that of the metropolitan ring where the station is located, which grew by $27 \cdot 3 \%$ (IECM, 2011a). These findings suggest that the implantation of a suburban rail station can have a positive influence on the attraction of population toward new urban developments.

\subsection{Line C-5}

Figure 3 shows the entire line C-5, with its stations, areas of influence and contrast zones. 
Transport

Volume 170 Issue TR6
New urban developments and commuter

rail: Madrid case study

Calvo, de Oña and Arán

\section{Offprint provided courtesy of www.icevirtuallibrary.com Author copy for personal use, not for distribution}

The sixth and seventh columns of Table 1 indicate the evolution of the population in the area of influence of the old and the new stations. The population increased around the new stations much more than around the old stations: 41 times greater percentagewise and 1.8 times greater in absolute terms. This result can be explained by the fact that most of the older stations are found in consolidated zones whose urban development took place long before the period of study. Besides, the growth in population around the new stations on line C-5 (250.9\%) is likewise much greater than the growth in the metropolitan ring where they are located, which amounts to $27 \cdot 3 \%$ (IECM, 2011a).

The contrast zone without urban railway is in an area of recent urban development (belonging to the expansion district of Vallecas) similar to the areas around the new stations of C-5 (Figure 3). As was the case of line C-4, the findings confirm (eighth and ninth columns of Table 1) that the population growth around the new stations was much greater ( 8.6 times percentage-wise; 1.2 times in absolute figures) than in the contrast zone with no urban rail. This heightened growth around new stations suggests that new urban developments that feature commuter rail have in fact attracted more population than the similar zones of recent development that are not serviced by any sort of urban railway.

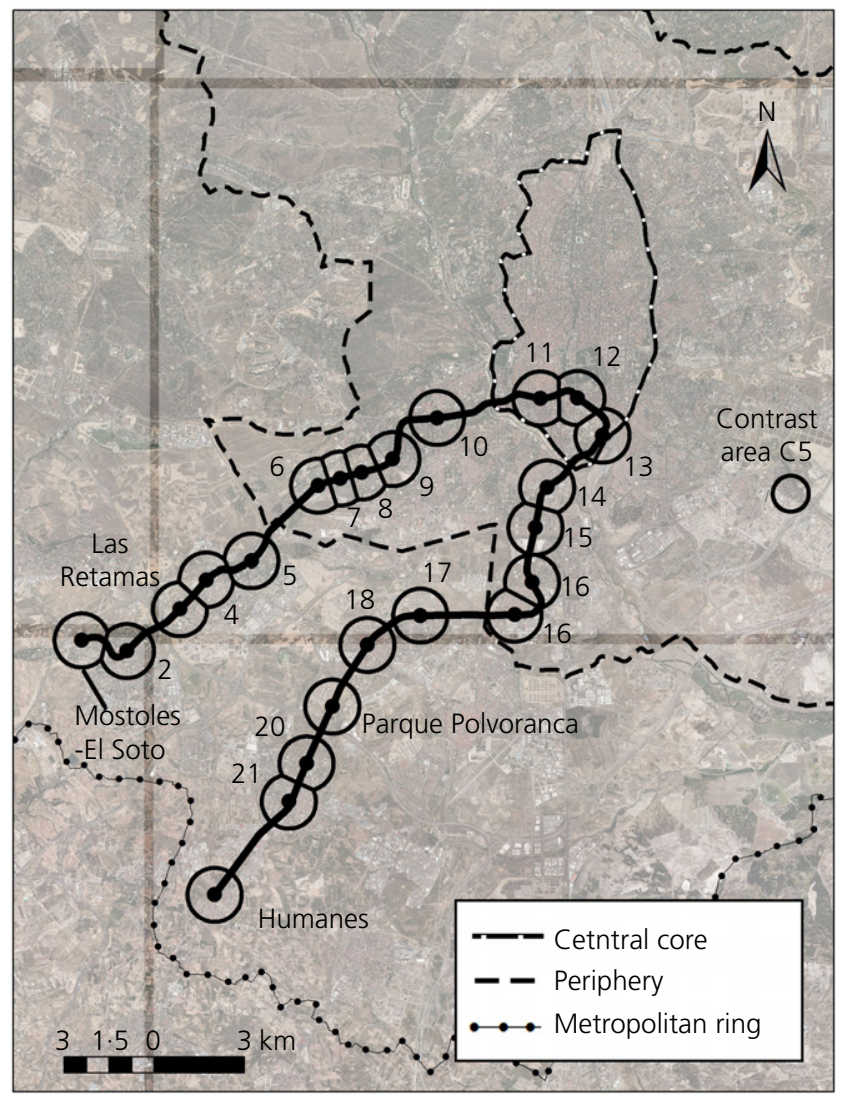

Figure 3. Commuter rail line C-5: stations, area of influence and contrast zone
On line C-5, given that three stations in newly developed areas were inaugurated during the period of study, a closer look should be taken at the initial conditions and subsequent evolutions that might be hidden by the mean values. To this end, the final three columns of Table 1 indicate, separately, the evolution of settlement around the new stations. Again, both the percentage-wise and the absolute growth (with the exception of Humanes) are much greater by the new stations than in the zone of contrast with no urban rail. Thus, earlier conclusions (those referring to the mean values) remain valid, despite the limitations of the comparison, in that the three new stations present somewhat different characteristics.

\section{Analysis of population concentration}

To assess the influence of distance to the station and the relationship between land use development and commuter rail station inauguration, the periods before and after opening the station $\left(t_{n}=0\right)$ were considered (with $t_{n}=-3$ and $t_{n}=3$ ).

\subsection{Line C-4}

Figure 4 and Table 2 show the evolution of the population before and after the inauguration of the Valdelasfuentes station (the only one of the new stations on line C-4 that was accompanied by new urban development) in terms of distance from the station.

According to Figure 4 and Table 2, around the station of Valdelasfuentes there was a very substantial previous population, but even so, the population continued to increase for the 7 years shown in the graph (from the beginning of 1998 to the end of 2004). Comparison of the regression slopes (parameter ' $a$ ' of Table 2) for before and after reveals that the growth of the population is greater after the inauguration in the station in 2001, above all in the radius $0-600 \mathrm{~m}$. It is also evident that the

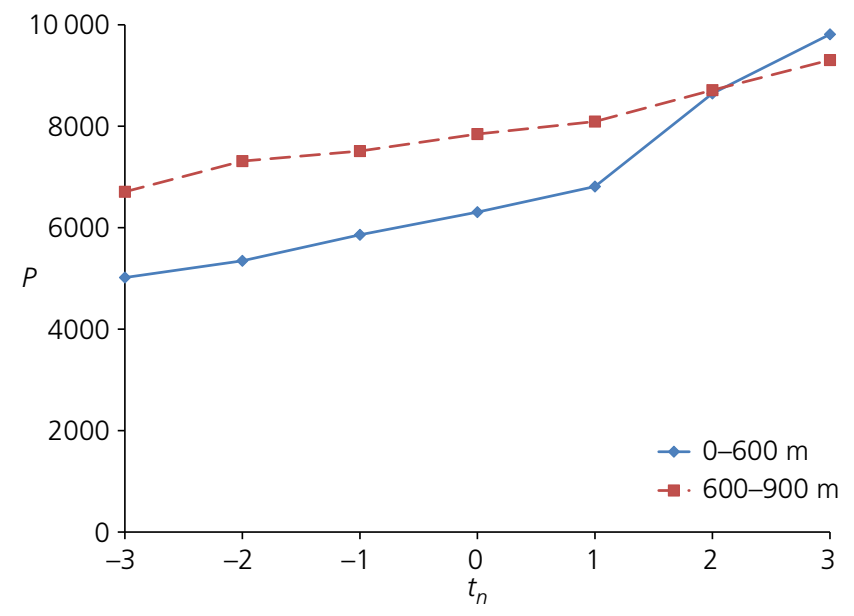

Figure 4. Valdelasfuentes station: population evolution before and after its inauguration according to the distance to the station. Source: Instituto de Estadística de la Comunidad de Madrid (IECM, 2011b) 
population tended to concentrate more quickly in the zone nearest the station, as the regression slopes in the central zone are greater than in the ring, particularly after inauguration. Hence, at the end of the seventh year, the population in the central zone is greater than the population of the ring. In short, the inauguration of the Valdelasfuentes station appears to have contributed to a greater settlement of population than any seen in previous years in the entire area of influence of the station; and this effect is most noteworthy in the zone closest to the station. Figure 5 shows the area of influence of Valdelasfuentes station in 1998 and 2004 (IECM, 2011b), where the recent development north of the station is clearly seen.

\subsection{Line C-5}

Figure 6 and Table 2 display the evolution of the population in terms of distance, in view of the mean value for the three new stations on line C-5.

Considering the three new stations of line C-5 (Figure 6 and Table 2) altogether, the growth of population in the area of influence is much greater after the inauguration, above all in the zone that is closest nearby. However, both before and after inauguration, the growth of population is greater in the ring than in the zone nearest the station, which gives rise to greater settlements of population in the zone farthest away.

Making the same calculations for each one of the stations separately, the results obtained for the mean of the three stations are seen to hold true for Humanes and Las Retamas, in contrast to Parque Polvoranca. This may be because the first two stations have in common a certain degree of previous urban development, which occupied above all the zone nearest to the station, unlike the case of Parque Polvoranca. For this reason, it is interesting to look more closely at the case of this station below (Figure 7). As the urban development in this case took place after the inauguration of the station, the period of analysis was prolonged by one additional year $\left(t_{n}=4\right)$.

It is quite clear from Figure 7 that the settlement of population around the Parque Polvoranca station (inaugurated in 2003) is negligible until 2 years after inauguration of the station. Thus, from 2005 onward there is a very substantial settlement of population. Moreover, the population tends to settle more quickly in the zone nearest the station. Figure 8, showing the area of influence of Parque Polvoranca in 2000 and 2007 (IECM, 2011b), reflects the growth taking place mostly in the north-west quadrant by the station.

\section{Conclusions}

The evolution of the population around the stations of two lines of Madrid's commuter rail service over a period of 11 years has been studied.

Line C-5, where new urban developments grew around three of the four new stations, showed a greater growth in population 


\section{Offprint provided courtesy of www.icevirtuallibrary.com Author copy for personal use, not for distribution}

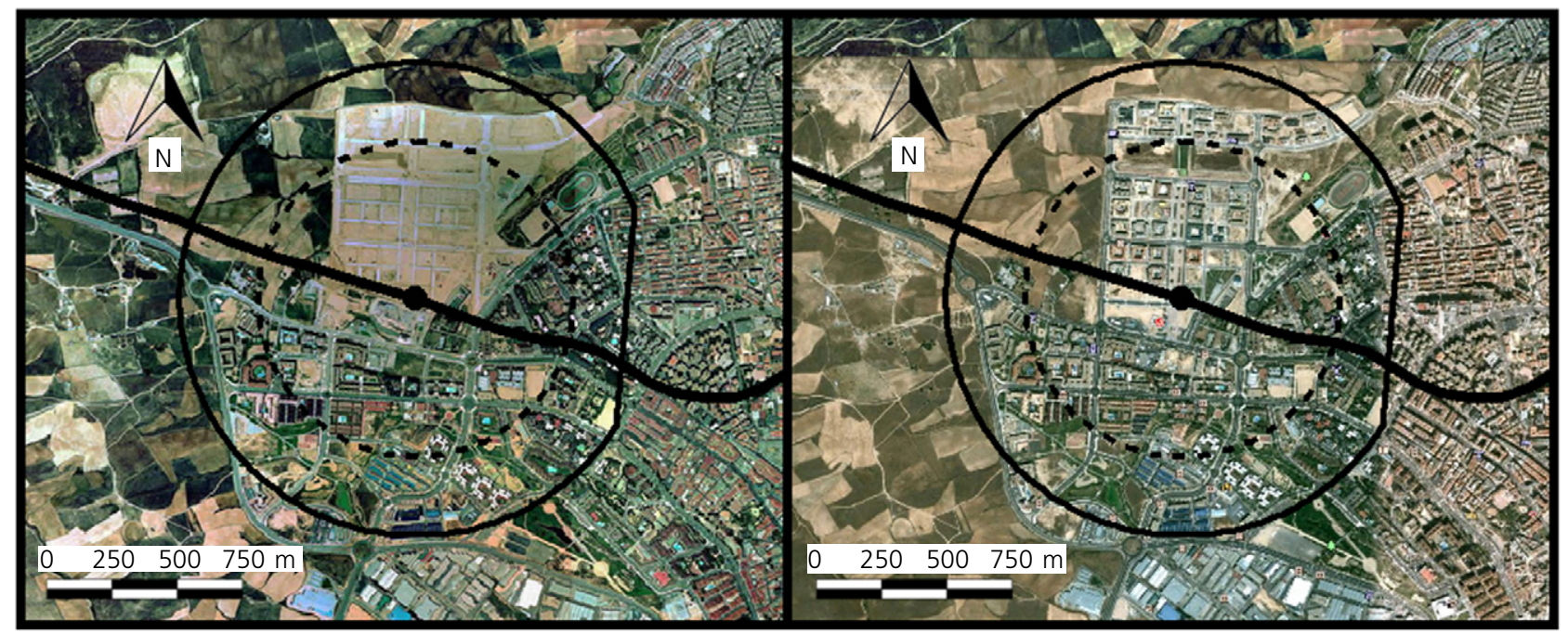

Figure 5. Orthophotos of the area of influence of Valdelasfuentes station before and after its inauguration. Source: Google Earth and IECM (2011b)

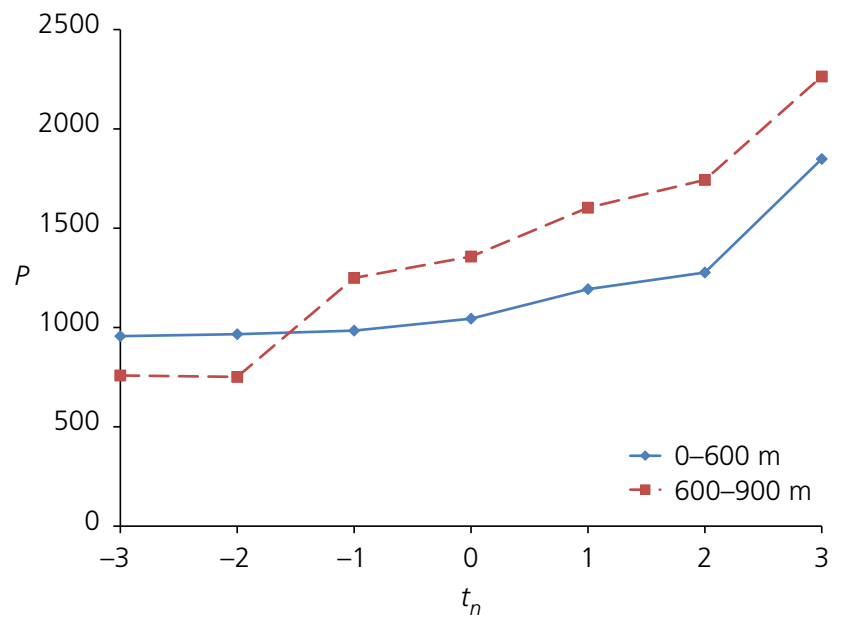

Figure 6. Population evolution before and after inauguration according to the distance to the station (average for $\mathrm{C}-5$ new stations)

near the new stations than near the older ones (41 times greater percentage-wise and 1.8 times greater in absolute terms). By contrast, recent development accompanied only one of the four new stations of line C-4, leading to a slightly greater growth in population near the old stations than near the new ones.

After this finding, the study focused on these four new stations surrounded by new urban developments, as in the other new stations there was no residential use, or else it was already completely consolidated.

The growth of the population during the period of study around the new stations linked to urban development is much greater than the growth seen for the zone of the realm of study

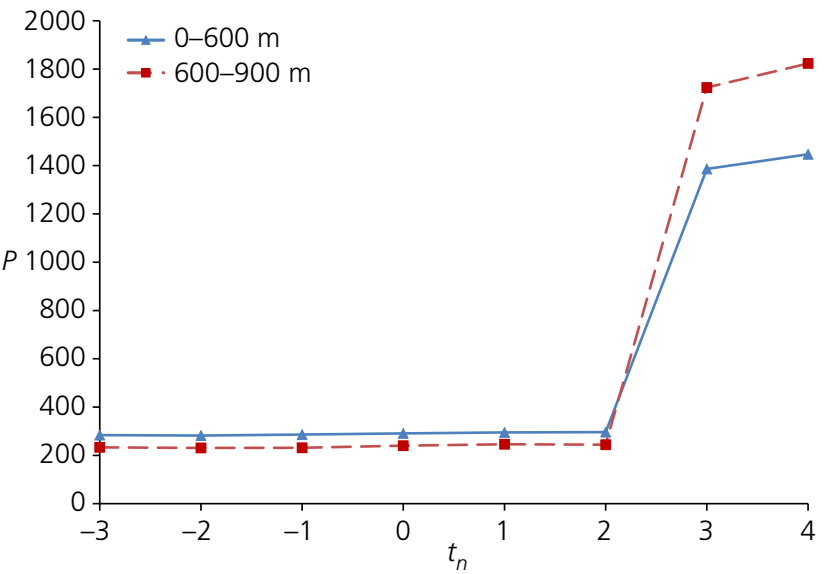

Figure 7. Parque Polvoranca station: population evolution before and after its inauguration according to the distance to the station. Source: Instituto de Estadística de la Comunidad de Madrid (IECM, 2011b)

(metropolitan ring) where these stations are located (roughly six times greater in Valdelasfuentes and roughly seven times greater in the new stations of C-5, percentage-wise).

The results (with a small, insignificant exception) show that the growth of population around new stations is much greater than in contrasting zones without urban rail (respectively $4 \cdot 0$ and 8.6 times greater, percentage-wise, in C-4 and C-5). In short, urban development in the area of influence of new commuter rail stations attracts many more inhabitants than similar urban developments that lack urban railway service.

Although results are not conclusive regarding the influence of the distance from a station to the settlements of population, 


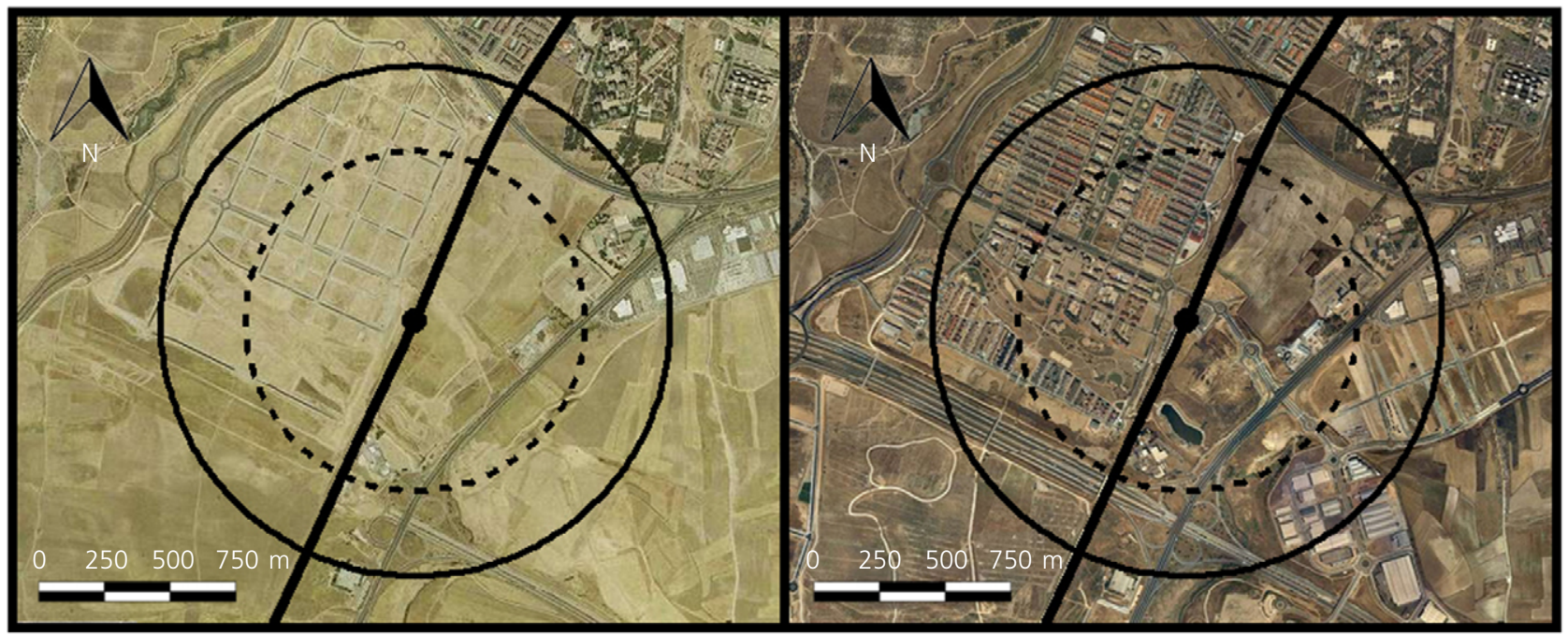

Figure 8. Orthophotos of the area of influence of the Parque Polvoranca station before and after its inauguration. Source: Google Earth and IECM (2011b)

the authors did confirm that there is a population 'boom' after the inauguration of new commuter rail stations, and that this post-inauguration boom is much greater in the zone closest to the station.

These findings indicate that, although accessibility is only one factor influencing population growth (other factors being the price of households, the type of building, changes in the motorisation index, etc.), the implantation of a commuter rail station can have a positive impact on settlement, attracting populations toward new urban developments.

\section{REFERENCES}

ADIF (Administrador de Infraestructuras Ferroviarias) (2011) Red de Cercanias. ADIF, Madrid, Spain. See http://www.adif.es (accessed 22/05/2011) (in Spanish).

Calvo F, de Oña J and Arán F (2013a) Impact of the Madrid subway on population settlement and land use. Land Use Policy 31(1-2) $627-639$.

Calvo F, de Oña J, Arán F and Nash A (2013b) The light rail transit experience in Madrid: effects on population settlement and land use. Transportation Research Record 2353: 82-91.

Cascetta E (ed.) (2009) Transportation Systems Analysis: Models and Applications. Springer, New York, NY, USA.

Chakraborty J and Armstrong M (1997) Exploring the use of buffer analysis for the identification of impacted areas in environmental equity assessment. Cartography and Geographic Information Systems 24(3): 145-157.

CRTM (Consorcio Regional de Transportes de Madrid) (2009) Light Rails and Tramways in Madrid Region. CRTM, Madrid, Spain.

Dong $\mathrm{H}$ (2016) If you build rail transit in suburbs, will development come? Journal of the American Planning Association 82(4): 316-326.

Du H and Mulley C (2007) The short-term land value impacts of urban rail transit: quantitative evidence from Sunderland, UK. Land Use Policy 24(1): 223-233.

García-López MA (2012) Urban spatial structure, suburbanization and transportation in Barcelona. Journal of Urban Economics 72(2-3): 176-190.
Giuliano G (1999) Land use impacts of transportation investments: highway and transit. In The Geography of Urban Transportation (Hansonn S (ed.)). Guildford Press, New York, NY, USA, pp. 305-340.

Gutiérrez J (1997) Análisis Dimensional del Transporte Público en Madrid. Consorcio Regional de Transportes, Madrid, Spain (in Spanish).

Gutiérrez J and García JC (2006) New spatial patterns of mobility within the metropolitan area of Madrid: towards more complex and dispersed flow networks. Journal of Transport Geography 15(1): $18-30$.

Gutiérrez J, Cristóbal C and Gómez G (2000) Accesibilidad peatonal a la red de metro de Madrid: efectos del plan de ampliación 1995-1999. Anales de la Geografia de la Universidad Complutense 20(1): 363-376 (in Spanish).

IECM (Instituto de Estadistica de la Comunidad de Madrid) (2011a) http://www.madrid.org/iestadis (accessed 17/05/2011).

IECM (2011b) http://www.madrid.org/nomecalles (accessed 17/05/2011). Jones SR (1981) Accessibility Measures: A Literature Review. Transport and Road Research Laboratory, Crowthorne, UK, TRRL Report 967.

Kasraian D, Maat K and van Wee B (2016) Development of rail infrastructure and its impact on urbanization in the Ranstad, the Netherlands. The Journal of Transport and Land Use 9(1): $151-170$.

Ko K and Cao X (2010) Impacts of the Hiawatha Light Rail Line on Commercial and Industrial Property Values in Minneapolis. Center for Transportation Studies, University of Minnesota, Minneapolis, MN, USA. See http://www.cts.umn.edu/ Publications/ResearchReports/pdfdownload.pl?id=1378 (accessed 27/02/2017).

Koenig JG (1980) Indicators of urban accessibility: theory and application. Transportation 9(2): 145-172.

Liu XB, Deng Y and Le Vine S (2016) Residential relocation in response to light rail transit investment: case study of the Hudson-Bergen Light Rail system. Journal of Modern Transportation 24(2): 139-144.

Mejía-Dorantes L, Paez A and Vassallo J (2011) Analyzing house prices to assess economic impacts of new public transport infrastructure: Madrid metro line 12. Transportation Research Record 2245 : 131-139. 
Ortúzar J and Willumsen L (2001) Modelling Transport. John Wiley \& Sons, New York, NY, USA.

O'Sullivan S and Morrall J (1996) Walking distances to and from light-rail transit stations. Transportation Research Record $\mathbf{1 5 3 8}$ 19-26.

Pagliara F and Papa E (2010) Urban rail systems investments: an analysis of the impacts on property values and residents' location. Journal of Transport Geography 19(2): 200-211.

Pirie GH (1979) Measuring accessibility: a review and proposal. Environment and Planning A 11(3): 299-312.

Reggiani A (ed.) (1998) Accessibility, Trade, and Locational Behaviour. Ashgate, Aldershot, UK

RENFE (Red Nacional de los Ferrocarriles Españoles) (2011) http://www. renfe.com (accessed 20/05/2011).
RICS (The Royal Institution of Chartered Surveyors) (2002) Transport Development Areas: A Study into Achieving Higher Density Development around Public Transport Nodes. RICS, London, UK. See http://www.rics.org/site/scripts/downloads.aspx?categoryID= 450 (accessed 15/02/2011).

TRB (Transportation Research Board) and Kittelson \& Associates, Inc. (2003) Transit Capacity and Quality of Service Manual, 2nd edn. Transportation Research Board, Washington, DC, USA, Transit Cooperative Research Program (TCRP) Report 100. UCM (Universidad Complutense de Madrid) (2002) Atlas de la Comunidad de Madrid en el Umbral del Siglo XXI. Imagen Socioeconómica de una Región Receptora de Inmigrantes. Department of Human Geography, Universidad Complutense de Madrid, Madrid, Spain (in Spanish).

\section{How can you contribute?}

To discuss this paper, please email up to 500 words to the editor at journals@ice.org.uk. Your contribution will be forwarded to the author(s) for a reply and, if considered appropriate by the editorial board, it will be published as discussion in a future issue of the journal.

Proceedings journals rely entirely on contributions from the civil engineering profession (and allied disciplines). Information about how to submit your paper online is available at www.icevirtuallibrary.com/page/authors, where you will also find detailed author guidelines. 